\title{
Recognition of depression and psychosis by young Australians and their beliefs about treatment
}

\author{
Annemarie Wright, Meredith G Harris, John H Wiggers, Anthony F Jorm, Sue M Cotton, Susy M Harrigan, \\ Rosalind E Hurworth and Patrick D McGorry
}

A dolescence and young adulthood are peak times for the onset of depression and psychotic disorders. ${ }^{1}$ Early detection and treatment have been shown to improve long-term outcomes ${ }^{2,3}$ and reduce the risk of future episodes of illness. ${ }^{4,5}$ Barriers to seeking help early for mental health problems include accessibility and availability of services, ${ }^{6,7}$ and limited "mental health literacy", 6-8 defined as "knowledge and beliefs about mental disorders which aid their recognition, management or prevention". 9 Indeed, aspects of mental health literacy, including patients' knowledge of symptoms and correct use of psychiatric labels, are associated with better detection of mental disorders by general practitioners. ${ }^{8}$

Previous surveys have highlighted deficits in mental health literacy in Australian and international populations, ${ }^{8,10}$ but there has been little research targeting young people. We aimed to assess

- young people's ability to recognise clinically defined depression and psychosis;

- the types of help they thought appropriate for these problems;

- their knowledge of appropriate treatments for these disorders;

- their perceived prognosis for these disorders; and

- whether young people's responses differed between age groups.

Our survey was conducted as a baseline measure for a community awareness campaign. Identifying gaps in mental health literacy may help to improve community education and the responsiveness of the health care system, thus ensuring that young

\section{ABSTRACT}

Objectives: To assess young people's ability to recognise clinically defined depression and psychosis, the types of help they thought appropriate for these problems, their knowledge of appropriate treatments, and their perceptions regarding prognosis.

Design: A cross-sectional telephone survey using structured interviews. Vignettes of a person with either depression or psychosis were presented, followed by questions related to recognition of the disorder, best forms of treatment and the prognosis.

Participants: A randomly selected sample of 1207 young people aged 12-25 years.

Setting: Melbourne, Victoria, and surrounding regional and rural areas.

Outcome measures: Responses to a mental health literacy questionnaire.

Results: Almost half the respondents were able to identify depression correctly, whereas only a quarter identified psychosis correctly. Counsellors and family or friends were the most commonly cited forms of best help, with family or friends preferred by the younger age group for depression. General practitioners were considered more helpful for depression, and psychiatrists and psychologists more helpful for psychosis. Most respondents considered counselling and psychotherapy to be helpful. However, more than half the respondents expressed negative or equivocal views regarding the helpfulness of recommended pharmacological treatments.

Conclusions: The limitations we identified in youth mental health literacy may contribute to the low rates of treatment and the long duration of untreated illness reported in other studies. There is a need for initiatives to enhance mental health literacy among young people, and those close to them, if benefits of early treatment are to be realised.

MJA 2005; 183: 18-23

people get appropriate help for these disorders in a timely manner.

\section{METHODS}

\section{Sample}

A cross-sectional telephone survey using structured interviews was conducted between March and July 2001. The telephone numbers for the sample were randomly selected from two metropolitan

ORYGEN Research Centre, University of Melbourne, Parkville, VIC.

Annemarie Wright, BAppSc(OT), MMedSc(HProm), Coordinator, The Compass Strategy; Meredith G Harris, MPH, MPASR, BA(Hons), Research Fellow; and Senior Research Officer, School of

Population Health, University of Queensland; Anthony F Jorm, DSc, Professorial Fellow; Sue M Cotton, BBSc(Hons), GradDipAppSci (Statistics), MAppSci (Statistics), Research Fellow (Statistician); Susy M Harrigan, BA, GradDipAppSci, MSc, Research Fellow (Statistician); Patrick D McGorry, MD, PhD, FRANZCP, Director.

Hunter Population Health, Hunter-New England Health Service, Wallsend, NSW.

John H Wiggers, BA(Hons), PhD, Director.

Centre for Program Evaluation, University of Melbourne, Melbourne, VIC.

Rosalind E Hurworth, PhD, MEd, PostGradDipSoc, Director.

Reprints will not be available from the authors. Correspondence: Ms Annemarie Wright, ORYGEN Research Centre, University of Melbourne, Locked Bag 10, Parkville, VIC 3052.

annemarie.wright@mh.org.au

regions in Melbourne and two adjacent semi-rural and rural regions using a CD-ROM listing of private household telephone numbers in the state of Victoria.

Respondents were eligible if they were aged $12-25$ years, able to understand and communicate in English, and, if they were under 18 years, a parent or guardian consented to their participation. When there was more than one eligible household member, the one with the most recent birthday was selected.

The sample was stratified by age (12-14 years; $15-17$ years; $18-25$ years) and region.

\section{Interview procedure}

Interviews were conducted by computerassisted telephone interview using a version of an earlier questionnaire. ${ }^{9}$

The interviewer presented a vignette involving either a male or female displaying symptoms meeting both ICD-10 11 and DSM-IV ${ }^{12}$ minimum diagnostic criteria for psychosis or depression. The disorder and 


\section{Vignettes presented to the respondents}

\section{Depression}

John (Mary) is a young person who has been feeling unusually sad and miserable for the last few weeks. He is tired all the time and has trouble sleeping at night. John (Mary) doesn't feel like eating and has lost weight. He can't keep his mind on his studies and his grades have dropped. He puts off making any decisions and even day-to-day tasks seem too much for him. His parents and teachers are very concerned about him.

\section{Psychosis}

John (Mary) is a young person who lives at home with his parents. He has had a few temporary jobs since finishing school but is now unemployed. Over the last 6 months he has stopped seeing his friends and has begun locking himself in his bedroom and refusing to eat with the family or to have a bath. His parents also hear him walking about in his bedroom at night while they are in bed. Even though they know he is alone, they have heard him shouting and arguing as if someone else is there. When they try to encourage him to do more things, he whispers that he won't leave home because he is being spied upon by the neighbour. They realise he is not taking drugs because he never sees anyone or goes anywhere.

\section{Summary of correct treatment and prognosis responses for depression and psychosis}

\begin{tabular}{|c|c|}
\hline & Depression guidelines $^{13}$ \\
\hline $\begin{array}{l}\text { Treating } \\
\text { professionals }\end{array}$ & $\begin{array}{l}\text { Health care clinicians, includir } \\
\text { general practitioners, psychia } \\
\text { paediatricians, psychologists, } \\
\text { social workers, occupational } \\
\text { therapists, nurses }\end{array}$ \\
\hline $\begin{array}{l}\text { Pharmacological } \\
\text { treatment }\end{array}$ & Antidepressants \\
\hline $\begin{array}{l}\text { Psychological } \\
\text { treatment }\end{array}$ & $\begin{array}{l}\text { Cognitive behaviour therapy } \\
\text { (a form of psychotherapy) }\end{array}$ \\
\hline Prognosis & $\begin{array}{l}80 \% \text { recover in first year, } 50 \% \\
\text { experience relapse }\end{array}$ \\
\hline
\end{tabular}

sex of the vignette character were randomly allocated to respondents (Box 1).

\section{Measures}

After reading the vignette, the interviewer asked two open-ended questions: "What, if anything, do you think is wrong with John (Mary)?" (problem recognition), and "How do you think John (Mary) could best be helped?" (best form of help). Unprompted responses were recorded.

Interviewers then read out to the respondents a list of people, and pharmacological and psychological treatments, that could potentially be helpful to the person described in the vignette. For the listed item, respondents were asked to indicate whether they thought the person or treatment would be "helpful", "harmful" or "make no difference" for the condition described in the vignette. Interviewers also recorded responses "depends" and "don't know". The respondents were then asked to indicate the extent of John's (Mary's) recovery if he (she) received the professional help the respond-

\section{Psychosis guidelines ${ }^{14}$}

Mental health clinicians, including

psychiatrists, psychiatry registrars, medical officers, occupational therapists, social workers, psychologists, nurses

Antipsychotics

Psychological/psychotherapeutic treatments; family work

$85 \%-90 \%$ recover in 6 months, $70 \%$ experience relapse

\section{Ethical approval}

Ethical approval for our study was obtained from the Ethics Committee of the Victorian Government Department of Human Services.

\section{Analysis}

We compared the demographic characteristics of the sample with those of the general population using the $\chi^{2}$ goodness-of-fit test comparing sample proportions with popula-

tion proportions. For these analyses the $\alpha$ level was set at 0.01 to minimise type I error.

For the open-ended questions, response categories were combined for analysis if their frequency was $2 \%$ or less, except for the response "nothing". To facilitate comparisons with earlier studies, interviewers recorded responses according to pre-coded response categories, based on a content analysis of responses to the same questions in an earlier survey. ${ }^{9}$ The exception was for the problem recognition question: the category "schizophrenia" was renamed "psychosis" as this is the more correct term, given the duration of symptoms described in the vignette. ${ }^{12}$ All psychotic disorders, including schizophrenia, were accepted as correct.

For the problem recognition question, a content analysis of responses that did not fit these pre-coded categories led to post-coding of three new categories: "other psychological problem" (which included the responses suicidal, nervous breakdown, split personality, scared/fearful/anxious, scared of leaving house/agoraphobia, and low self-esteem/self-confidence); "physical problem" (which included the responses tired/rundown, glandular fever, sleeping disorder/insomnia, and chronic fatigue syndrome); and "other miscellaneous" (which included the responses bullying/peer pressure, boredom/lack of motivation, problems with friends/partners, family problems and "other").

Similarly, for the "best form of help" question a new category "other" was created which included the responses teachers/ school counsellor and "other" responses. A new variable called "correct help" was created by combining the responses for the categories "counsellor/psychologist", "doctor", "psychiatrist", and "medication".

We compared the proportion of responses between the two vignettes and two age groups (12-17 years; $18-25$ years) using $\chi^{2}$ analysis.

\section{RESULTS}

\section{Sample}

The study response rate was $89.7 \%$ (Box 3), with 606 respondents given the depression vignette and 601 given the psychosis vignette.

\section{Problem recognition}

In response to the open-ended question "What, if anything, do you think is wrong with John (Mary)?" almost half the respondents identified depression cor- 


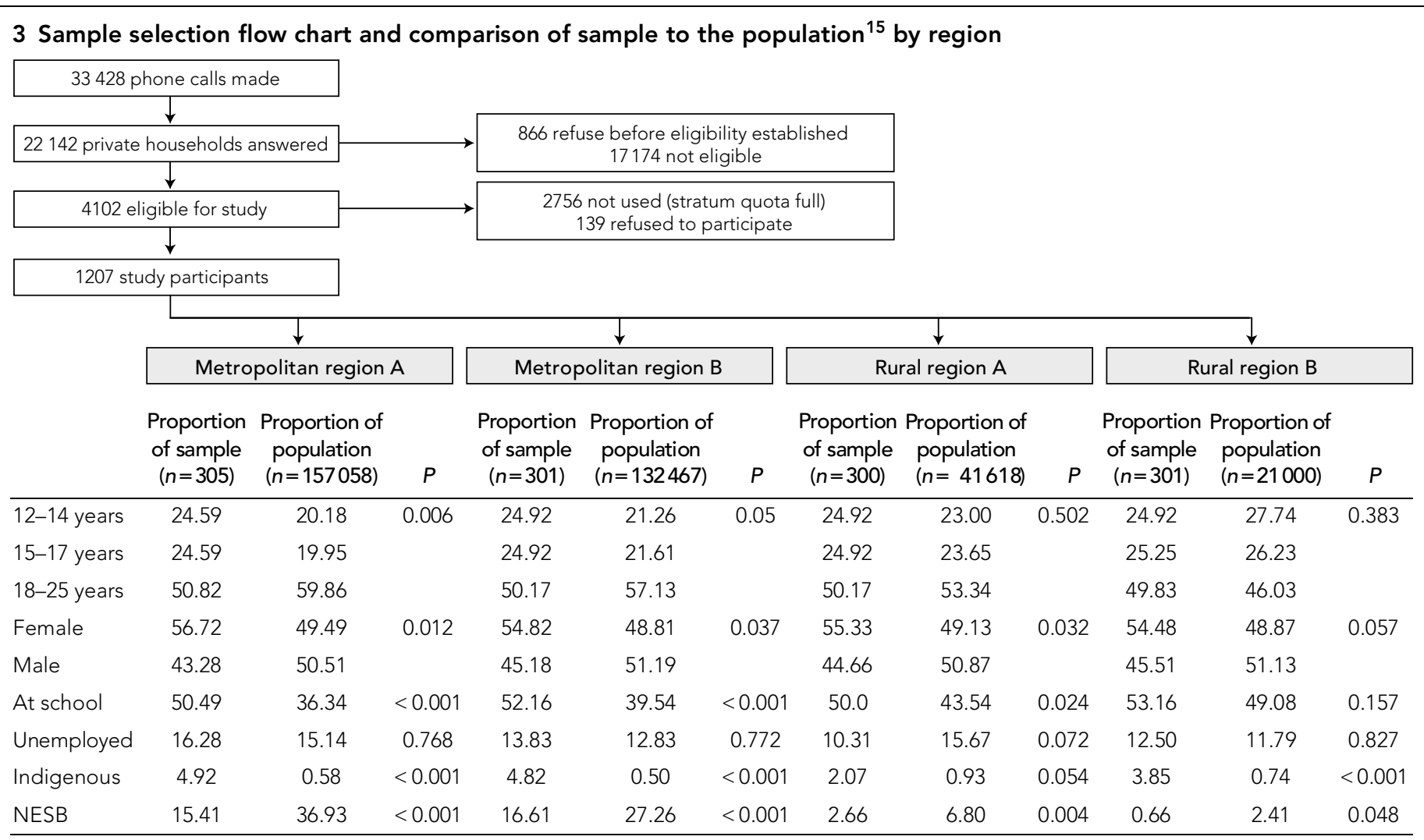

NESB $=$ non-English speaking background.

rectly, but only a quarter identified psychosis correctly (see Box 4). Younger respondents were significantly less likely to recognise both depression and psychosis. A variety of labels related to mental health were used by respondents to describe both vignettes including "mental illness", "stress", "psychological/mental/emotional problems", "eating disorder", "other psychological problem". When these were combined with the "depression" and "schizophrenia" responses, a similar proportion of respondents were able to recognise that the vignettes were related to a mental health problem. For both vignettes, about $13 \%$ of respondents indicated they did not know what was wrong.

\section{Best form of help}

Slightly more than half the respondents gave a correct answer to the question "How do you think John (Mary) could best be helped?", with a lower proportion of those given the depression vignette being correct than those given the psychosis vignette (Box 4). The older age group provided the correct response more frequently than the younger group. Of the respondents who were able to correctly identify depression, 59.3\% [175/295] were able to nominate a correct form of help, compared with only 47.2\% [144/305] of those who were not able to correctly identify depression $\left(\chi_{1}^{2}=8.831 ; P=0.003\right)$. Likewise, $75 \%$ [114/152] of respondents who correctly identified psychosis were able to nominate a correct form of help, compared with only 59.2\% [263/444] of those who did not correctly identify psychosis $\left(\chi_{1}^{2}=12.109 ; P=0.001\right)$.

Seeing a counsellor or psychologist was nominated as the best source of help by about a quarter of respondents for the depression and psychosis vignettes. Family and friends were commonly reported as the best source of help, but were more commonly cited for depression than psychosis, and more frequently by younger age groups. GPs were more often cited as a preferred source of help for depression than for psychosis, while psychiatrists were more commonly cited for psychosis than depression. Overall, GPs were more frequently preferred by older respondents.

\section{Helpfulness rating of treating professionals}

Seventy per cent or more of respondents thought each of the recommended profes- sionals would be helpful for the person described in both vignettes (Box 4).

Psychologists and psychiatrists were significantly more frequently nominated as helpful for the person in the psychosis vignette than for the person in the depression vignette. In contrast, "family doctor/ GP" was significantly more frequently nominated as helpful for the person in the depression vignette as opposed to the psychosis vignette. Most professional groups were more frequently cited as helpful by the older age group for both depression and psychosis.

\section{Helpfulness rating of pharmacological treatments}

More than half the respondents expressed either negative or equivocal views regarding the helpfulness of pharmacological treatments (Box 4). Antidepressants were considered harmful by $29.3 \%$ [176/600] of respondents for the treatment of depression, while 15.9\% [95/596] considered antipsychotics to be harmful for psychosis. Younger respondents more frequently described antidepressants as helpful for depression. There was no significant difference in the proportion of respondents 
who rated the correct pharmacological treatment as helpful for the two disorders.

\section{Helpfulness rating of psychological treatments}

Counselling or psychotherapy was considered by most respondents to be helpful for the treatment of the people described in the depression vignette and the psychosis vignette, with significantly more respondents regarding this as helpful for psychosis compared with depression (Box 4). Older respondents more frequently cited counselling or psychotherapy as helpful for psychosis.

\section{Perceived prognosis}

Almost all respondents indicated that a person with the nominated condition would make some form of recovery (depression 96.7\% [589/600]; psychosis 96.5\% [575/ 596]), with almost a third indicating the correct prognosis.

\section{DISCUSSION}

Depression was far more readily recognised than psychosis by the young people surveyed, but belief in the helpfulness of recommended interventions was generally greater for psychosis. Older respondents were better able to correctly identify disorders and displayed a greater belief in the effectiveness of most recommended forms of treatment. Younger respondents were more likely to recommend seeking help from family and friends.

We believe this is the first study of its kind focusing specifically on young people using a measurement tool with established validity. ${ }^{16}$ However, this is also the first time the tool has been used in a telephone interview, and its validity in this format has not yet been established.

The high response rate among those eligible to participate adds strength to the generalisability of the results. However, the survey was conducted in geographically defined areas of Victoria only, and the findings may not apply to other areas of the state or to other states and territories in Australia. The over-representation of Indigenous young people in the sample is likely to be due to the under-reporting of Indigenous status in census data. ${ }^{17}$ Those speaking a language other than English at home were under-represented, and this is likely to be an artefact of the participant eligibility criteria. Young peo-

\section{Comparison of responses between vignettes and age groups}

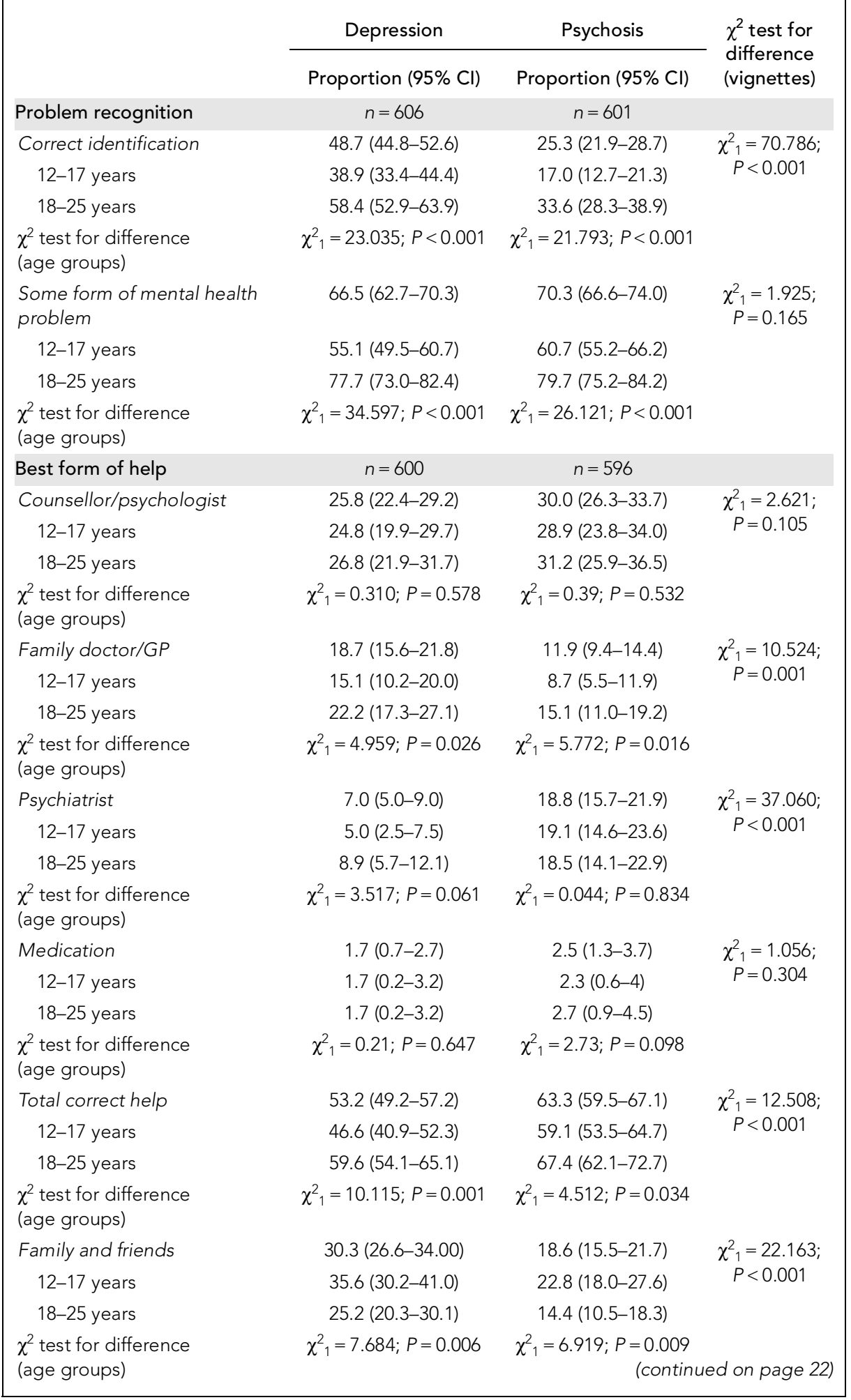

ple still at school were over-represented; hence, the observed pattern of health literacy is likely to be an overestimate of that in the population from which the sample was drawn, given the positive association between education, literacy and health literacy. ${ }^{18}$

While most aspects of the clinical practice guidelines (current at the time) used to determine the accuracy of participant 
4 Comparison of responses between vignettes and age groups (continued from page 21)

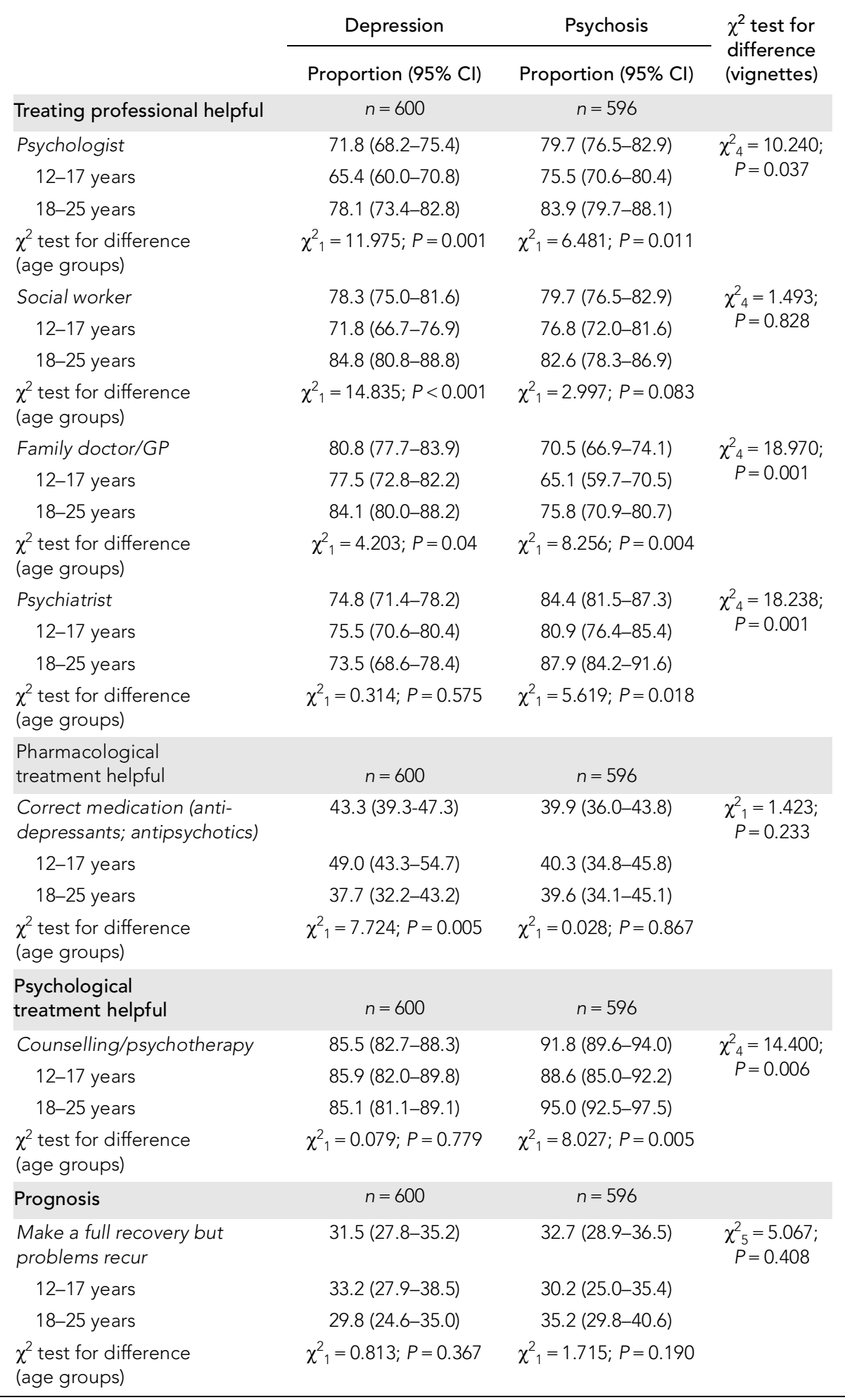

responses maintain their relevance today, some elements have since been superseded or do not apply universally. Cognitive behavioural therapy is acknowledged as preferable for milder forms of depression, ${ }^{19}$ and, while the efficacy of antidepressants is acknowledged in those aged 18 years and over, they are not considered to be as efficacious in adolescents. ${ }^{13}$

Consistent with previous and recent studies, 9,20,21 depression was correctly identified more often than psychosis. In common with the only previous youth study, ${ }^{21}$ family and friends and a counsellor/psychologist were the most frequently mentioned sources of help, although a psychiatrist was as frequently mentioned as helpful for the psychosis vignette.

Levels of correct recognition of both depression and psychosis were lower than those reported in the most recent and methodologically comparable adult study. $^{20}$ In the study by Jorm and colleagues, ${ }^{20}$ adults more frequently suggested recommended sources of help, particularly doctor and psychiatrist; however, when asked whether the people recommended would be helpful, the young respondents in this study were more positive about social workers and psychiatrists, the latter particularly for depression. A similar pattern to this and other adult studies ${ }^{8}$ was noted in our study - psychiatrists and psychologists were considered more helpful for psychosis and GPs more helpful for depression. Views regarding the helpfulness of medications were similar. The most striking difference was that counselling/psychotherapy was considered to be helpful by $30 \%-40 \%$ more young people, although this may be due to the adult study seeking responses on psychotherapy alone.

The mental health literacy of the young people in our study was often less than that recently reported in the adult population. One possible explanation is that young people have less life experience. Another is that population mental health literacy may have increased since our study was conducted, as a result of the implementation of beyondblue: the national depression initiative in the intervening period. $^{22}$

The practical relevance of these findings may be limited, as responses in a telephone interview context may not necessarily predict behaviour when a person is actually confronted with mental illness. However, previous studies with adults suggest there is some predictive value. ${ }^{8}$

Important questions arising from this study are:

- Is this level of mental health literacy adequate; and

- What level of mental health literacy is it reasonable to expect?

The levels reported here may be considered to be encouraging and may be due, in part, to the success of local and national school-based interventions such as MindMatters. ${ }^{23}$ However, mental health problems 
are the major contributor to overall burden of disease for young people aged 15-24 years, ${ }^{24}$ and improvements in mental health literacy could contribute to a reduction in disease burden by increasing the number of young people receiving treatment for mental health problems. Thus, it could be argued that mental health literacy deserves as much attention as that currently afforded to other major youth health issues, such as prevention of road trauma. Given the developmentally appropriate tendency of young people, particularly those under 18, to seek help from family and friends, these social supports are also an important target for mental health literacy improvement.

Efforts to improve mental health literacy in the adult population have yielded promising results. ${ }^{22,25}$ Focusing community education on the identified gaps in mental health literacy during adolescence and young adulthood, when the risk of onset is high, could potentially make a substantial contribution to reducing the burden of disease associated with mental illness in the longer term.

\section{ACKNOWLEDGEMENTS}

Our study was supported by a grant from ANZ Trustees and beyondblue: the national depression initiative. ANZ Trustees and beyondblue: the national depression initiative had no role in study design, data collection, analysis, interpretation or writing of the article.

\section{COMPETING INTERESTS}

None identified.

\section{REFERENCES}

1 Burke KC, Burke JD Jr, Regier DA, Rae DS. Age at onset of selected mental disorders in five community populations. Arch Gen Psychiatry 1990; 47: 511-518.

2 Kupfer DJ, Frank E, Perel JM. The advantage of early treatment intervention in recurrent depression. Arch Gen Psychiatry 1989; 46: 771775.

3 Loebel AD, Lieberman JA, Alvir JM, et al. Duration of psychosis and outcome in firstepisode schizophrenia. Am J Psychiatry 1992; 149: 1183-1188.

4 Kroll L, Harrington R, Jayson D, et al. Pilot study of continuation cognitive-behavioral therapy for major depression in adolescent psychiatric patients. J Am Acad Child Adolesc Psychiatry 1996; 35: 1156-1161.

5 Johnstone EC, Crow TJ, Johnson AL, MacMillan JF. The Northwick Park Study of first episodes of schizophrenia. I. Presentation of the illness and problems relating to admission. $\mathrm{Br} J$ Psychiatry 1986; 148: 115-120.

6 Sawyer MG, Arney FM, Baghurst PA, et al. Mental health of young people in Australia. Canberra: Australian Government Department of Health and Aged Care, 2000.
7 Lincoln C, Harrigan S, McGorry PD. Understanding the topography of the early psychosis pathways. An opportunity to reduce delays in treatment. Br J Psychiatry Suppl 1998; 172: 2125.

8 Jorm AF. Mental health literacy. Public knowledge and beliefs about mental disorders. Br J Psychiatry 2000; 177: 396-401.

9 Jorm AF, Korten AE, Jacomb PA, et al. "Mental health literacy": a survey of the public's ability to recognise mental disorders and their beliefs about the effectiveness of treatment. Med $J$ Aust 1997; 166: 182-186.

10 Lauber C, Nordt C, Falcato L, et al. Do people recognise mental illness? Factors influencing mental health literacy. Eur Arch Psychiatry Clin Neurosci 2003; 253: 248-251.

11 World Health Organization. The ICD-10 classification of mental and behavioural disorders: diagnostic criteria for research. Geneva: WHO, 1993.

12 American Psychiatric Association. Diagnostic and statistical manual of mental disorders. 4th ed. Text revision. Washington, DC: American Psychiatric Association, 2000.

13 National Health and Medical Research Council. Depression in young people. Clinical practice guidelines. Canberra: AGPS, 1997.

14 University of Melbourne. The Australian clinical practice guidelines for early psychosis. Melbourne: Early Psychosis Prevention and Intervention Centre, 1998.

15 Australian Bureau of Statistics. 2001 Census of population and housing: selected social and housing characteristics for Statistical Local Areas in Victoria. Sydney: ABS, 2001. (Catalogue No. 2015.2.)

16 Jorm AF, Korten AE, Jacomb PA, et al. Helpfulness of interventions for mental disorders: beliefs of health professionals compared with the general public. Br J Psychiatry 1997; 171: 233-237.
17 Australian Bureau of Statistics. Population characteristics, Aboriginal and Torres Strait Islander Australians. Canberra: ABS, 2003. (Catalogue No. 4713.0.)

18 Health literacy: report of the Council on Scientific Affairs. Ad Hoc Committee on Health Literacy for the Council on Scientific Affairs, American Medical Association. JAMA 1999; 281: 552-557.

19 Harrington R, Whittaker J, Shoebridge P, Campbell F. Systematic review of efficacy of cognitive behaviour therapies in childhood and adolescent depressive disorder. BMJ 1998; 316: 1559-1563.

20 Jorm AF, Christensen H, Griffiths KM. The public's ability to recognise mental disorders and their beliefs about treatment: changes in Australia over 8 years. Aust N Z J Psychiatry 2005. In press.

21 Keys Young. Research and consultation among young people on mental health issues. Final report. Canberra: Australian Government Department of Health and Family Services, 1997.

22 Jorm AF, Christensen H, Griffiths KM. The impact of beyondblue: the national depression initiative on the Australian public's recognition of depression and beliefs about treatments. Aust N Z J Psychiatry 2005; 39: 248-254.

23 Wyn J, Cahill H, Holdsworth R, et al. MindMatters, a whole-school approach promoting mental health and wellbeing. Aust N Z J Psychiatry 2000; 34: 594-601.

24 Mathers C, Vos T, Stevenson C. The burden of disease and injury in Australia. Canberra: Australian Institute of Health and Welfare, 1999. (AlHW Catalogue No. PHE-17.)

25 Johannessen JO, McGlashan TH, Larsen TK, et al. Early detection strategies for untreated firstepisode psychosis. Schizophr Res 2001; 51: 3946.

(Received 30 Nov 2004, accepted 19 May 2005)
Wright A, Harris MG, Jorm AF, et al.

Recognition of depression and psychosis by young Australians and their beliefs about treatment. Med J

Aust 2005; 183 (1): 18-23. () Copyright 2005. The Medical Journal of Australia - reproduced with permission. 